\title{
Xylitol production by Saccharomyces cerevisiae overexpressing different xylose reductases using non-detoxified hemicellulosic hydrolysate of corncob
}

\author{
Anushree Kogje ${ }^{1,2} \cdot$ Anand Ghosalkar ${ }^{2}$
}

Received: 10 March 2016/ Accepted: 25 May 2016/Published online: 7 June 2016

(c) The Author(s) 2016. This article is published with open access at Springerlink.com

\begin{abstract}
Xylitol production was compared in fed batch fermentation by Saccharomyces cerevisiae strains overexpressing xylose reductase (XR) genes from Candida tropicalis, Pichia stipitis, Neurospora crassa, and an endogenous gene GRE3. The gene encoding a xylose specific transporter (SUT1) from P. stipitis was cloned to improve xylose transport and fed batch fermentation was used with glucose as a cosubstrate to regenerate NADPH. Xylitol yield was near theoretical for all the strains in fed batch fermentation. The highest volumetric $\left(0.28 \mathrm{gL}^{-1} \mathrm{~h}^{-1}\right)$ and specific $\left(34 \mathrm{mgg}^{-1} \mathrm{~h}^{-1}\right)$ xylitol productivities were obtained by the strain overexpressing GRE3 gene, while the control strain showed $7.2 \mathrm{mgg}^{-1} \mathrm{~h}^{-1}$ specific productivity. The recombinant strains carrying XR from $C$. tropicalis, $P$. stipitis, and $N$. crassa produced xylitol with lower specific productivity of $14.3,6.8$, and $6.3 \mathrm{mgg}^{-1} \mathrm{~h}^{-1}$, respectively, than GRE3 overexpressing strain. The glucose fed as cosubstrate was converted to biomass and ethanol, while xylose was only converted to xylitol. The efficiency of ethanol production was in the range of 38-45\% of the theoretical maximum for all the strains. Xylitol production from the non-detoxified corncob hemicellulosic hydro-
\end{abstract}

Anand Ghosalkar

anandghosalkar@praj.net

Anushree Kogje

anushree.kogje@gmail.com

1 Department of Technology, Savitribai Phule Pune University, Pune, Maharashtra 411007, India

2 Division of Praj Industries Limited, Praj-Matrix - R \& D Centre, 402/403/1098, Urawade, Pune, Maharashtra 412115, India lysate by recombinant $S$. cerevisiae was reported for the first time. Xylitol productivity was found to be equivalent in the synthetic xylose as well as hemicellulosic hydrolysate-based media showing no inhibition on the $S$. cerevisiae due to the inhibitors present in the hydrolysate. A systematic evaluation of heterologous XRs and endogenous GRE3 genes was performed, and the strain overexpressing the endogenous GRE3 gene showed the best xylitol productivity.

Keywords Xylitol - Saccharomyces cerevisiae - Xylose reductase $\cdot$ Corn cob hemicellulosic hydrolysate

\section{Introduction}

Xylitol, the sugar alcohol is a promising polyol due to its application as a low calorie sweetener. It can be used for its antimicrobial properties to prevent dental and other infections (Nevoigt 2008). Xylitol is conventionally produced by hydrolysis and hydrogenation of xylan to xylitol under high temperature and pressure conditions. In spite of very high conversion efficiency, this technology has certain constrains viz. requirements of high pressure, temperature, expensive catalyst, and extensive downstream operations (Leathers 2003). Microorganisms convert xylose to xylitol by the cofactor-dependent xylose reductase (XR or Xyll) enzyme (Saha 2003; Cocotle-Ronzon et al. 2012). The majority of essential cofactor NADPH/NADH for the XR activity is regenerated through pentose phosphate pathway (PPP) (Bengtsson et al. 2009; Schwartz et al. 2012). Several microorganisms have been screened and studied with respect to their ability for assimilation of xylose as carbon source and conversion to xylitol. Extensive research has been conducted to isolate and identify the suitable yeasts 
for xylitol production (Barbosa et al. 1988; Parajo et al. 1998a). Xylitol producing yeasts, such as P. stipitis, $C$. tropicalis, C. guilliermondii, D. hansenii (Mohamad et al. 2015), and $K$. marxianus (Zhang et al. 2013), have been studied for the optimization of the fermentation parameters, utilization of various nutrients, and fermentation of xylose rich hemicellulosic hydrolysate obtained from different sources of pretreated biomass (Parajo et al. 1998a, b; Dominguez et al. 1996; Ping et al. 2013). These organisms were preferred, as they exhibited efficient conversion of xylose to xylitol. Several reports on Candida species involved studies on the fermentation of pretreated biomass hydrolysates. Ghindea et al. (2010) have provided a review on various microorganisms studied for xylose transport and xylitol production.

Saccharomyces cerevisiae does not naturally utilize xylose as a carbon source, yet was preferred due to its GRAS (Generally Regarded As Safe) status. S. cerevisiae carries GRE3 gene encoding a non-specific NADPH-dependent aldose reductase that converts xylose to xylitol (Kuhn et al. 1995). Many researchers have attempted to overexpress heterologous xylose reductases from $P$. stipitis or several Candida species in $S$. cerevisiae mainly for ethanol or xylitol production. However, strains overexpressing endogenous GRE3 gene have not been evaluated systematically for xylitol production using media derived from pretreated biomass. The byproducts generated during the pretreatment of biomass, such as furans, weak acids, and phenolics, inhibit the cell metabolism individually or synergistically (Almeida et al. 2007; Hu et al. 2009). S. cerevisiae acquires tolerance to some inhibitors, such as HMF and furfural, due to the presence of some oxidoreductase enzymes (Heer et al. 2009).
The recombinant strains developed for xylitol production exhibit low productivity and xylose consumption rate in biomass derived media (Menon et al. 2010; Karhumaa et al. 2005). In the previous reports, $P$. stipitis XR has been cloned and overexpressed in $S$. cerevisiae for xylose metabolism. A detailed review on the various genetic engineering strategies of $S$. cerevisiae and fermentation of xylose containing media has been provided by Chu and Lee (2007). In some cases, multiple genes have been altered through or overexpressed, but endogenous gene expression levels have been rarely modified for xylitol production.

The present investigation deals with the evaluation of the conversion of xylose to xylitol by $S$. cerevisiae strains overexpressing different XR genes. The gene SUT1 was cloned to avoid the limitation of xylose transportation in the $S$. cerevisiae cells. The xylitol production by the recombinant $S$. cerevisiae strains was compared in hemicellulosic hydrolysate of corn cob with the fed batch fermentation process.

\section{Materials and methods}

\section{Cultures, growth media, and plasmids used}

Pichia stipitis ATCC 58784, Candida tropicalis ATCC 9968, and Neurospora crassa NCIM 870 were used as a source of xylose reductase genes for which accession numbers have been provided in Table 1 ( $P s X R, C t X R$, and $N c X R$, respectively). GRE3 gene was amplified from $S$. cerevisiae, and $E$. coli TOP10F' was used as intermediate host for the cloning and multiplication of the plasmid vector. The host strain used was $S$. cerevisiae BY4741. The

Table 1 Primers used in this study

\begin{tabular}{|c|c|c|c|}
\hline Primer & Target gene (accession no.) & Primer sequence & Restrction Sites \\
\hline$P s X R-\mathrm{F}$ & P. stipitis XR (NC_009045) & 5'-GAC GGA TCC ATG CCT TCT ATT AAG TTG AAC-3' & BamHI \\
\hline$P s X R-\mathrm{R}$ & & 5'-TAACTCGAGTTGTCCCAGTCCCATGGGTCGTTGAAT-3' & XhoI \\
\hline$C t X R-F$ & C. tropicalis XR (NW_003020040) & 5'-GAGCGGATCCATGTTTAAATTTTTCACTTCTCCAA-3' & BamHI \\
\hline$C t X R-\mathrm{R}$ & & 5'-CGCCACTCGAGTTAAACAAAGATTGGAATGTTGT-3' & XhoI \\
\hline GRE3-F & S. cerevisiae GRE3 (NC_001140) & 5'-CTCGGATCCATGTCTTCACTGGTTACTCTT C-3' & BamHI \\
\hline GRE3-R & & 5'-ATACTCGAGTCAGGCAAAAGTGGGGAATTTA-3' & XhoI \\
\hline$N c X R-\mathrm{F}$ & N. crassa XR (NC_026501) & 5'-CAGAATTCATGGTTCCTGCTATCAAGCTCAA-3' & EcoRI \\
\hline$N c X R-\mathrm{R}$ & & 5'-TCAATCGATCTAACCGAAAATCCAGAGGTTCT-3' & Cla I \\
\hline SUT1-F & P. stipitis SUT1 (NC_009068) & $\begin{array}{l}\text { 5'-TACACGTACTTAGTCGCTGAAGCTCTTCTATGATGTCTT } \\
\text { CTCAAGATATTCCTTCAG-3' }\end{array}$ & NA \\
\hline SUT1-R & & $\begin{array}{l}\text { 5'-AGGTACGAACTCGATTGACGGCTCTTCTACCTTAAA } \\
\text { CATGTTCGTCAACAGGC-3' }\end{array}$ & NA \\
\hline
\end{tabular}

Restriction sites are indicated in bold

$N A$ not applicable 

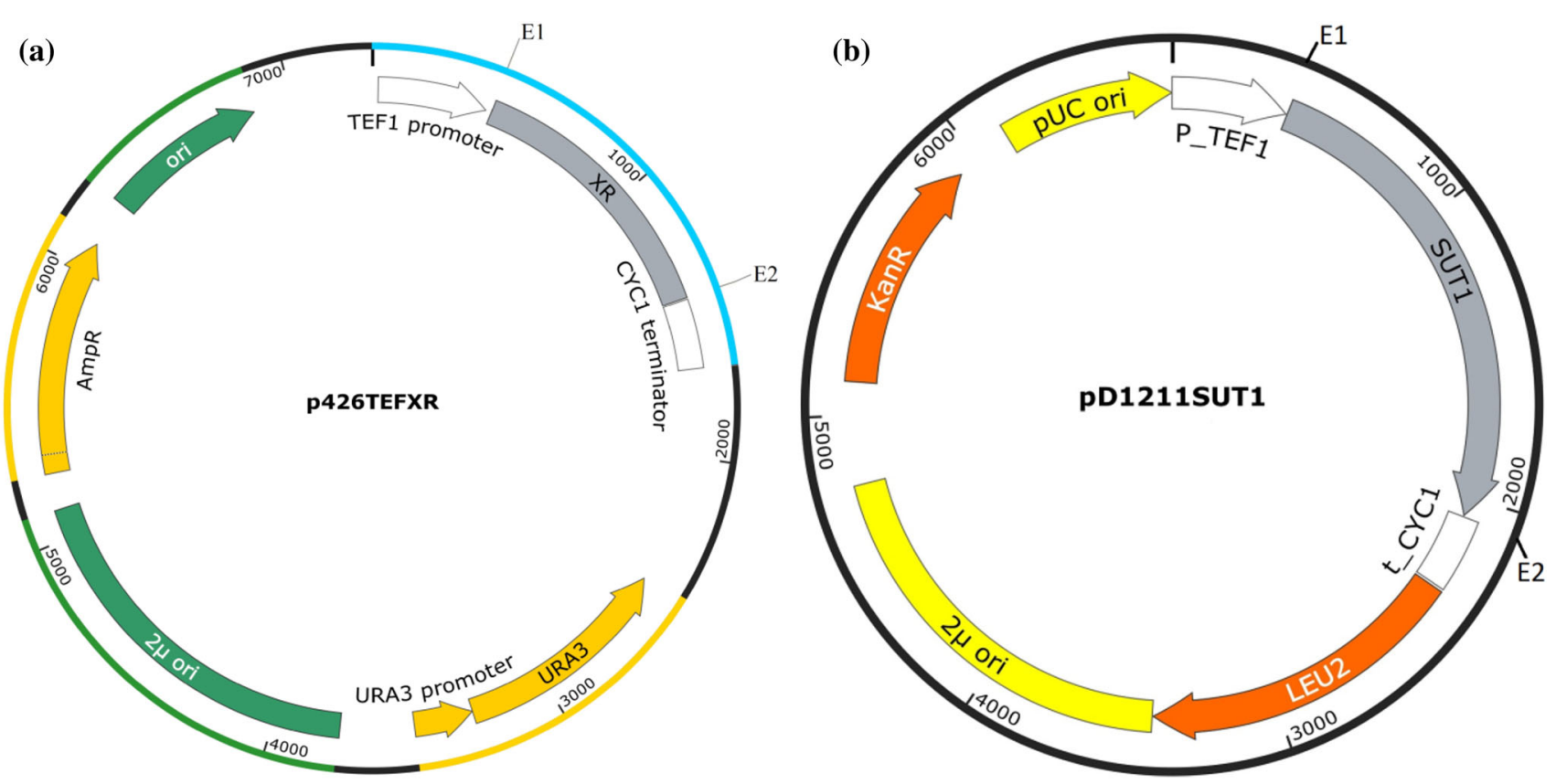

Fig. 1 Plasmid map of a p426TEF with cloned XR, b pD1211 with SUT1, where E1 and E2-Restriction site in forward and reverse primers, respectively, used for cloning

yeast cultures of $P$. stipitis, $C$. tropicalis, and $S$. cerevisiae were grown and maintained in YPD media ( $10 \mathrm{~g}$ Yeast Extract, $20 \mathrm{~g}$ Peptone, $20 \mathrm{~g}$ Glucose per liter). Neurospora crassa was grown in FD medium containing per liter $5 \mathrm{~g}$ Peptone, $3 \mathrm{~g}$ Beef Extract, $1.5 \mathrm{~g}$ Potasium phosphate monobasic, and $1.5 \mathrm{~g}$ Potasium phosphate dibasic. Recombinant $S$. cerevisiae BY4741 cultures were grown in $\mathrm{SD}$ (Synthetic dropout) medium containing glucose $20 \mathrm{~g}$ and Yeast Nitrogen Base $6.7 \mathrm{~g}$ per liter supplemented with essential amino acids except uracil and leucine (Amberg et al. 2005). This selective medium was also used as prefermentation growth medium (PF). Luria-Bertani medium and ampicillin (80 ppm) were used for E. coli growth under selective pressure.

The shuttle expression vector plasmid p426TEF (ATCC 87369) was used for cloning and episomal expression of the selected XR genes in $S$. cerevisiae. Cloning of the $P$. stipitis SUT1 gene was done in the shuttle expression vector pD1211 (DNA 2.0 Inc., CA, US) as per the kit protocol. Both the vectors have $2 \mu$ origin of replication, high copy number, and a strong promoter TEF1 and CYC1 terminator flanking the multiple cloning site for high-level constitutive expression of the respective genes.

\section{Genetic manipulation of microorganisms}

The genes were PCR amplified from the genomic DNA of the source organism using the primers listed in Table 1.
Genomic DNA preparation from yeasts or fungus was done by the Genomic DNA isolation kit Zymo-D6005 (Zymo Research). The plasmids and the genes were digested with the corresponding restriction enzymes, as indicated in Table 1, and purified by the Qiagen Gel Extraction kit. Ligation of the double digested gene and vector was done by the T4 DNA ligase. All the enzymes were purchased from NEB. Transformation of the E. coli cells was done by the standard heat shock method, and recombinant cells were selected on the plates of selective medium. Bacterial plasmid purification was performed with the Plasmid Mini kit 25 (Qiagen, Netherlands), and recombinant plasmids p426TEF carrying XR genes and the plasmid pD1211SUT1 were co-transformed into yeast cells by Frozen-EZ Yeast transformation II kit (Zymo Research). The recombinant cells were selected on the SD media plates without uracil and leucine. Yeast plasmids were purified using Zymoprep Yeast Plasmid Miniprep II kit (Zymo Research) and used for verification. All the kits used for yeast samples were procured from Zymo Research, USA. The map for the plasmid carrying XR genes has been shown in Fig. 1. Transformed yeast colonies were screened and verified by PCR using gene specific primers. The confirmed colonies were grown in selective medium and stored as glycerol stocks for further use. The features of the plasmids used and the strains developed for this study are described in Tables 2 and 3, respectively.

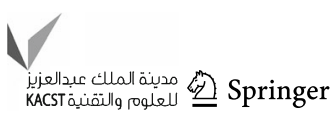


Table 2 Plasmids used in the present study

\begin{tabular}{|c|c|c|c|}
\hline Plasmid & $\begin{array}{l}\text { Markers } \\
\text { (bacterial, } \\
\text { yeast) }\end{array}$ & $\begin{array}{l}\text { Expression cassette } \\
\text { (promoter, terminator) }\end{array}$ & $\begin{array}{l}\text { Gene } \\
\text { cloned }\end{array}$ \\
\hline p426TEF & $\mathrm{Amp}^{\mathrm{R}}$, Ura3 & $\mathrm{P}_{\mathrm{TEF}}, \mathrm{T}_{\mathrm{CYC} 1}$ & - \\
\hline pD1211 & $A m p^{R}$, Leu2 & $\mathrm{P}_{\mathrm{TEF}}, \mathrm{T}_{\mathrm{CYC} 1}$ & - \\
\hline p426TEFPsXR & $A m p^{R}$, Ura3 & $\mathrm{P}_{\mathrm{TEF}}, \mathrm{T}_{\mathrm{CYC} 1}$ & $P s X R$ \\
\hline $\mathrm{p} 426 \mathrm{TEF} C t X R$ & $A m p^{R}$, Ura3 & $\mathrm{P}_{\mathrm{TEF}}, \mathrm{T}_{\mathrm{CYC} 1}$ & $C t X R$ \\
\hline $\mathrm{p} 426 \mathrm{TEF} N c X R$ & $A m p^{R}$, Ura3 & $\mathrm{P}_{\mathrm{TEF}}, \mathrm{T}_{\mathrm{CYC} 1}$ & $N c X R$ \\
\hline p426TEFGRE3 & $A m p^{R}$, Ura3 & $\mathrm{P}_{\mathrm{TEF}}, \mathrm{T}_{\mathrm{CYC} 1}$ & GRE3 \\
\hline pD1211SUT1 & $A m p^{R}$, Leu2 & $\mathrm{P}_{\mathrm{TEF}}, \mathrm{T}_{\mathrm{CYC} 1}$ & SUT1 \\
\hline
\end{tabular}

\section{Preparation of the hemicellulosic hydrolysate of corn cob}

Corn cob having total solid content of $92 \%$ on the weight basis was subject to mechanical shear to obtain the particle size of $20-40 \mathrm{~mm}$, which was then soaked in water for nearly $30 \mathrm{~min}$. The feed containing $30 \%$ solids was constantly supplied with steam, $2 \%$ sulphuric acid, and $1 \%$ oxalic acid on the basis of the solid content for pretreatment. The pretreatment was performed in the continuous digester for $20 \mathrm{~min}$ at high pressure and temperature of 6 bars and $160{ }^{\circ} \mathrm{C}$, respectively, maintained using the acids and steam. The pretreated slurry of the hemicellulosic hydrolysate of corn cob thus generated contained about $18-20 \%$ solids. The hemicellulosic hydrolysate of corn cob was used for fermentation trials, for which the composition is provided in Table 4 .

\section{Fermentation studies}

The fermentation inoculum was prepared in two stages, where glycerol stock of the strains was used to start the first stage culture. The stage one culture $\left(10 \% \mathrm{vv}^{-1}\right)$ was then used to inoculate the stage two culture. In both stages of the inoculum preparation, cultures were grown in the PF medium at pH 5.5, $150 \mathrm{rpm}$ and incubated at $30{ }^{\circ} \mathrm{C}$ for 24 to $30 \mathrm{~h}$ to achieve $\mathrm{OD}_{600 \mathrm{~nm}}$ of about 15 . Fermentation was started by inoculating $15 \% \mathrm{vv}^{-1}$ stage two inoculum to attain an initial
Table 4 Composition of hemicellulosic hydrolysate of corn cob

\begin{tabular}{ll}
\hline Component & Concentration $\left(\mathrm{gL}^{-1}\right)$ \\
\hline Xylose & 65 \\
Glucose & 7 \\
Arabinose & 6 \\
Acetic acid & 7 \\
HMF + Furfueal & 0.7 \\
Phenolics & $3-4$ \\
\hline
\end{tabular}

$\mathrm{OD}_{600 \mathrm{~nm}}$ of 2 in the fermentation broth. Concentrated stocks of YP (10X), glucose and xylose $\left(50 \mathrm{gL}^{-1}\right.$ each), were sterilized separately, and corn cob hemicellulosic hydrolysate was heated at $80{ }^{\circ} \mathrm{C}$ for $10 \mathrm{~min}$. The stock solution of was used for the fermentation trials with synthetic xylose, while the hemicellulosic hydrolysate was used as the source of xylose in corn cob hemicellulosic hydrolysate-based fermentation. The synthetic xylose stock or the hemicellulosic hydrolysate was added to YPD to obtain a final xylose concentration of $40 \mathrm{gL}^{-1}$ in $400 \mathrm{ml}$ of fermentation broth. Fermentation of xylose to xylitol by the recombinant strains overexpressing SUTI and an XR gene was performed by fed batch fermentation, as described by Chung et al. (2002), with some modification. Fed batch fermentation was carried out in the $1 \mathrm{~L}$ reactor (BioFlo/CelliGen 115, New Brunswick, USA) at temperature $30{ }^{\circ} \mathrm{C}$, agitation of $150 \mathrm{rpm}$, and at $0.2 \mathrm{vvm}$ aeration. Process was operated in batch mode for first $24 \mathrm{~h}$ after inoculation. Once the initial glucose was completely consumed, glucose stock solution $(300 \mathrm{~g} / \mathrm{L})$ was continuously fed at a flow rate of $2.5 \mathrm{~mL} / \mathrm{h}$. The $\mathrm{pH}$ of medium was maintained at 5.5 using $4 \mathrm{~N} \mathrm{NaOH}$ or $4 \mathrm{~N} \mathrm{HCl}$. Antifoam was added as per requirement. All the chemicals were purchased from HiMedia (India).

\section{Analysis of fermentation samples}

The fermentation samples were analyzed for concentrations of glucose, xylose, xylitol, ethanol, and other byproducts by HPLC (1100 system, Agilent Technologies, USA). Separation was done using the Aminex HPX-87H

Table 3 Strains used in the present study

\begin{tabular}{lll}
\hline Strain & Description & Reference \\
\hline S. cerevisiae BY4741 & MATa his3 1 leu2 40 met15 40 ura3 40 (ATCC No. 201388) & Brachmann et al. (1998) \\
ScpGT & BY4741 + p426TEFGRE3 + pD1211SUT1 & This study \\
ScpCT & BY4741 + p426TEFCtXR + pD1211SUT1 & This study \\
ScpPT & BY4741 + p426TEFPsXR + pD1211SUT1 & This study \\
ScpNT & BY4741 + p426TEFNcXR + pD1211SUT1 & This study \\
\hline
\end{tabular}


column $(300 \times 7.8 \mathrm{~mm}$ i.d. $)($ Bio-Rad, USA $)$ at a column temperature of $55^{\circ} \mathrm{C}$. Sulfuric acid $(5 \mathrm{mM})$ was used as mobile phase at a flow rate of $0.6 \mathrm{~mL} / \mathrm{min}$, and the compounds were detected using the refractive index detector.

\section{Dry cell weight measurement}

The fermentation samples were centrifuged at $8000 \mathrm{rpm}$ for $5 \mathrm{~min}$. The cell pellet was washed with distilled water. The cells were resuspended in $1 \mathrm{~mL}$ water and allowed to dry in a glass plate in the vacuum oven at $60{ }^{\circ} \mathrm{C}$. The dry cell weight was calculated in $\mathrm{g}$ DCW per liter.

\section{Specific xylose reductase activity measurement}

Fermentation samples were centrifuged at $8000 \mathrm{rpm}$ for $5 \mathrm{~min}$ to harvest $50 \mathrm{mg}$ cells and were washed with distilled water. Crude cell-free extract was prepared by treating cells with $200 \mu \mathrm{l}$ Y-PER ${ }^{\mathrm{TM}}$ Yeast Protein Extraction Reagent (Thermo Scientific, USA) and $4 \mu$ Protease Inhibitor Cocktail (Sigma Aldrich, USA) and then centrifugation at $13,000 \mathrm{rpm}$ for $10 \mathrm{~min}$. The supernatant or crude cell-free extract was immediately used for the enzyme assay and protein measurement or stored at $-80{ }^{\circ} \mathrm{C}$. The specific XR activity was estimated by the method reported earlier (Verduyn et al. 1985). The assay reaction contained $150 \mu \mathrm{M}$ NADPH, $500 \mathrm{mM}$ Potassium phosphate buffer having pH 6, $200 \mu \mathrm{M}$ xylose, and diluted crude cell-free extract in a total assay volume of $1 \mathrm{~mL}$. Reaction mixture was allowed to stand on ice for $10 \mathrm{~min}$, and absorbance was read at $340 \mathrm{~nm}$ using the spectrophotometer (Schimadzu UV2450, Japan). One unit of $\mathrm{XR}$ activity is defined as the amount of enzyme required to oxidize one $\mu \mathrm{M} \mathrm{NADPH}$ in $1 \mathrm{~min}$. Protein content was determined by the standard method (Lowry et al. 1951). The specific XR activity was calculated by dividing the XR activity by the protein concentration in the samples.

\section{Mitotic stability measurement}

The recombinant strains exhibited loss of vector during growth on non-selective media in fermentation studies. The stability of the recombinant strains was measured as the relative viability count. The fermentation broth was diluted appropriately and spread onto plates of selective (SD) and non-selective (YPD) media to estimate the fraction of recombinant cells that had lost the plasmid.

\section{Statistical analysis}

The data were collected from at least two different and independent experiments. The statistical analysis was done using student's $t$ test null hypothesis and represented as mean \pm standard error (S.E.).

\section{Results and discussion}

\section{Genetic manipulation of microorganisms}

Organisms carrying xylose reductase genes were identified on the basis of the high-specific XR activities viz. $P$. stipitis, C. tropicalis, and N. crassa based on the previous reports (Woodyer et al. 2005) along with the endogenous GRE3 gene of $S$. cerevisiae. The gene SUT1 from $P$. stipitis, encoding a xylose transporter was cloned along with XR genes in S. cerevisiae to increase the overall xylose metabolism. Saccharomyces cerevisiae does not carry an endogenous xylose transporter and it depends on the non-specific hexose sugar transporters (HXT) for xylose uptake (Hamacher et al. 2002). The xylose consumption rate of the $S$. cerevisiae strains engineered for xylose metabolism can be significantly improved by the expression of the SUT1 gene (Katahiraa et al. 2008). Overexpression of SUT1 gene was done to avoid any limitations of xylose uptake and to evaluate performance of different XRs cloned in the recombinant S. cerevisiae. Genetically engineered strains of $S$. cerevisiae were developed and verification was done by gene specific PCR.

\section{Fermentation using recombinant $S$. cerevisiae strains}

The functioning of xylose reductase is essentially dependent on cofactor NADPH, which could lead to a cofactor imbalance within cells. The fed batch fermentation process allowed the elimination of the redox imbalance arising due to the accumulation of $\mathrm{NADP}^{+}$in the cell by maintaining carbon flux through PPP. Glucose limited fed batch fermentation process was adopted to achieve NADPH regeneration for the activity of xylose reductases essential for xylitol production, as shown in Fig. 2. The fermentation process was operated in batch mode for first $24 \mathrm{~h}$ to attain cell growth up to $9 \mathrm{gL}^{-1}$ dry cell weight. Xylose consumption was not observed in the batch mode. Glucose feeding was done to allow continuous cofactor regeneration in the fed batch phase of xylose fermentation. Hector et al. (2011) showed that NADPH is regenerated mainly through PPP during glucose metabolism. The glucose feed rate of $0.75 \mathrm{gh}^{-1}$ was maintained which was just enough for the growth and did not allow its accumulation in the broth to avoid catabolite repression of xylose consumption in the recombinant $S$. cerevisiae. Xylitol productivities of the recombinant strains were compared with the control. 

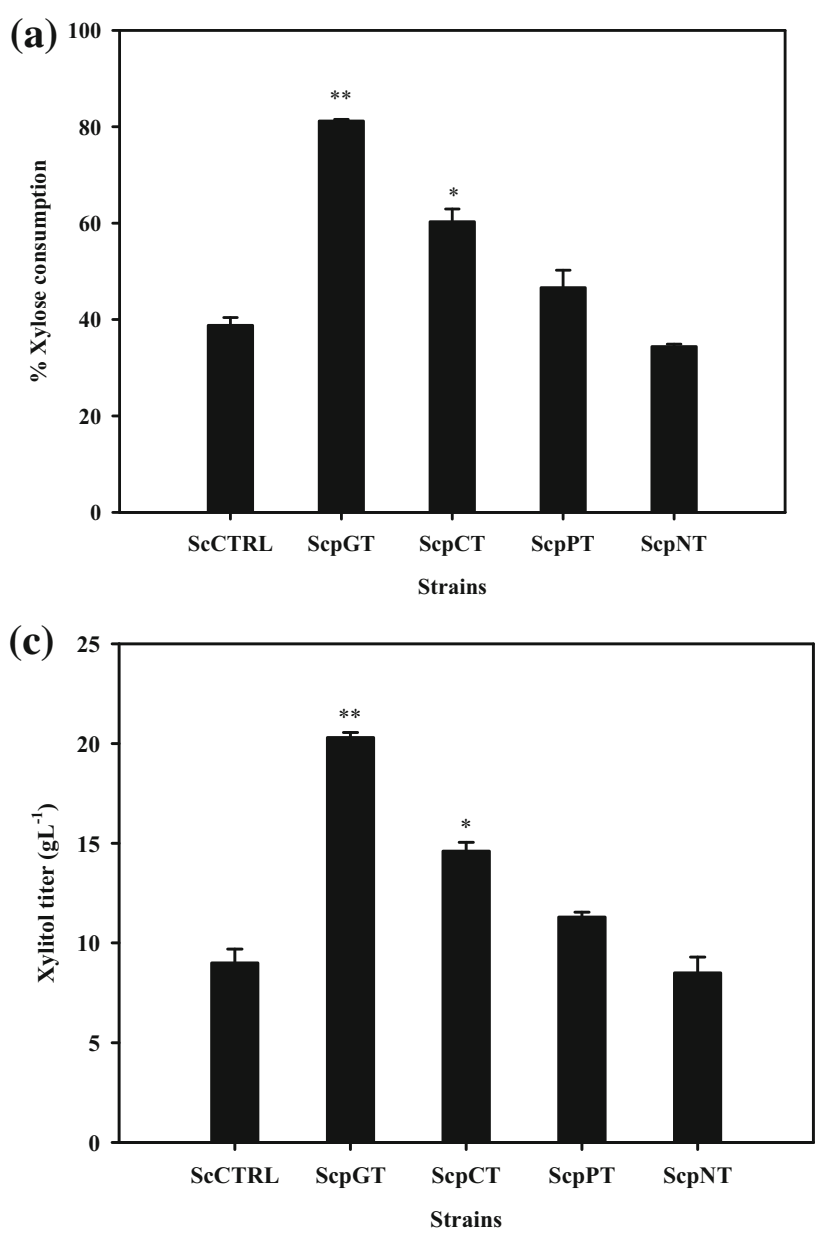

Fig. 2 Percent xylose consumption a, specific xylitol productivity $\mathbf{b}$, xylitol titer $\mathbf{c}$, and specific xylose reductase activity $\mathbf{d}$ in fed batch fermentation with double recombinant strains overexpressing

All the recombinant and the control strains showed nearly theoretical yield of xylitol on consumed xylose.

Xylitol production rate by strains containing different xylose reductases has been summarized in Fig. 2a-d. The control $S$. cerevisiae strain carrying empty plasmid consumed about $38.8 \%$ of the initial xylose and produced xylitol at a near theoretical yield indicating no further xylitol metabolism. Figure 2a shows that the strain overexpressing GRE3 gene showed $81 \%$ consumption of the initial amount of xylose, and it produced xylitol with a specific productivity of $34 \mathrm{mgg}^{-1} \mathrm{~h}^{-1}$, which was about fivefold higher than the control strain. The strain overexpressing XR from $C$. tropicalis also showed a significant increase of twofold over the control strain. Overexpression of the Pichia and Neurospora XR showed specific xylitol productivity of 9.8 and $6.6 \mathrm{mgg}^{-1} \mathrm{~h}^{-1}$, respectively, which was not a significant increase over the control strain $\left(7.9 \mathrm{mgg}^{-1} \mathrm{~h}^{-1}\right.$ ), as shown in Fig. 2b. The final titer of xylitol obtained during fermentation by different strains is
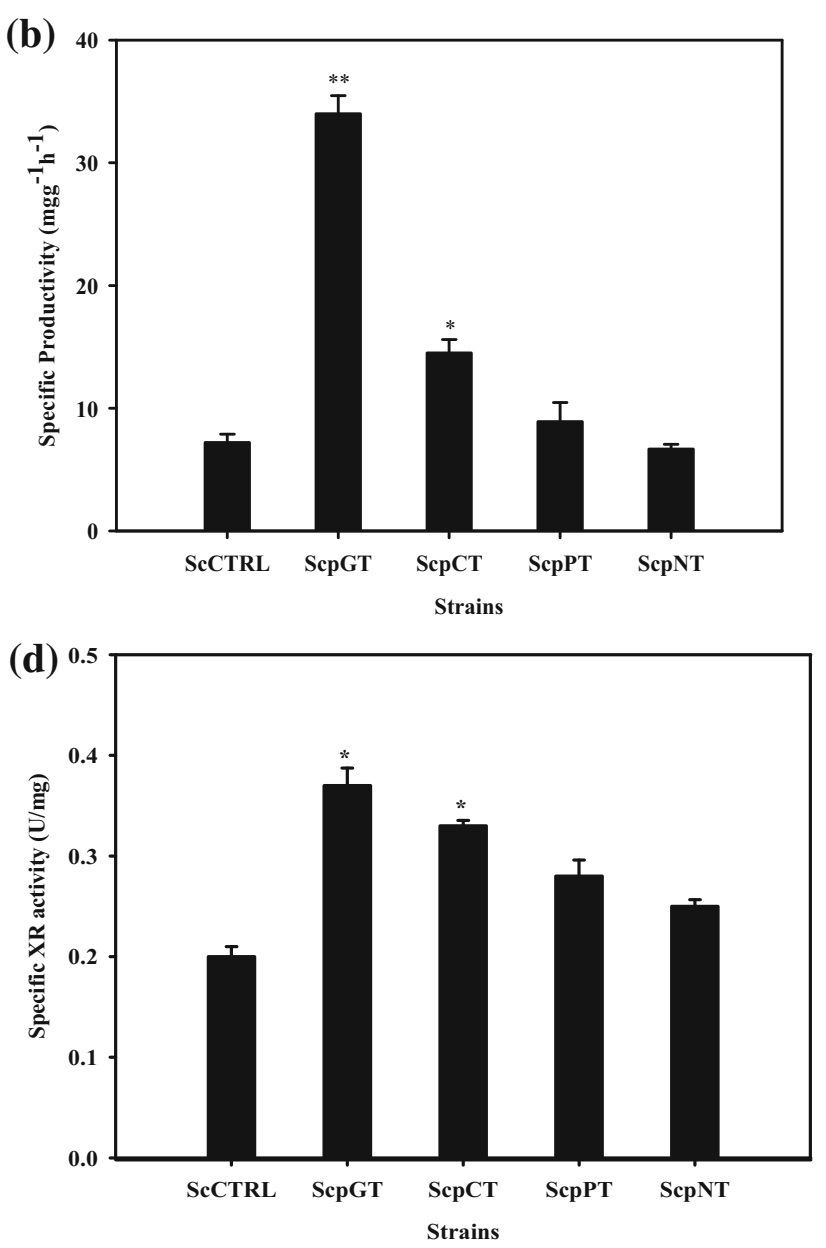

different $X R$ and SUT1 genes. Difference is indicated as significant $\left({ }^{*} p<0.05, * * p<0.005\right)$ when compared to the control group

shown in Fig. 2c. The results indicated that the strain overexpressing GRE3 gene produced the highest xylitol up to $21 \mathrm{gL}^{-1}$ followed by the strain carrying $C$. tropicalis XR with $15 \mathrm{gL}^{-1}$. The other recombinant strains produced xylitol at similar titers to the control strain. The highest amount of xylitol obtained in the broth by the strain carrying GRE3 gene was twofold higher than the control strain.

Comparison of the recombinant strains overexpressing $X R$ and SUT1 showed that increase in the specific enzyme activity of recombinant xylose reductase enzyme in $S$. cerevisiae showed a corresponding increase in xylitol production by the recombinant strains. The biochemical characteristics of different XRs in their native hosts have been summarized in Table 5 (Woodyer et al. 2005). There was a difference between the catalytic efficiency of these reductases in their native hosts and their activities in $S$. cerevisiae observed in this study (Table 5). In the case of the catalytic activities in their native hosts, the XR from 
Table 5 Properties of xylose reductases in their native systems (Woodyer et al. 2005)

\begin{tabular}{llll}
\hline Organism & $\begin{array}{l}\text { Enzyme Mol } \\
\mathrm{wt}(\mathrm{kDa})\end{array}$ & $\begin{array}{l}K_{\mathrm{m}} \text { for xylose } \\
\left(\mathrm{mM}^{-1} \mathrm{~min}^{-1}\right)\end{array}$ & $\begin{array}{l}\mathrm{K}_{\mathrm{cat}} \\
\left(\mathrm{min}^{-1}\right)\end{array}$ \\
\hline S. cerevisiae & 33 & 13.6 & 860 \\
C. tropicalis & 58 & 35 & $\mathrm{ND}$ \\
P. stipitis & 65 & 42 & 1500 \\
N. crassa & 53 & 34 & 3600 \\
\hline
\end{tabular}

Neurospora showed the highest turnover number $\left(K_{\text {cat }}\right)$ with xylose and NADPH as substrates.

Xylose metabolism by $S$. cerevisiae has been attributed to the endogenous non-specific NADPH-dependent aldoketoreductase enzyme encoded by the gene GRE3. This gene is reported to be expressed in stress-related responses, such as hypoxia, heat shock, starvation, heavy metals, osmotic, and ionic stresses, including lithium (Celton et al. 2012; Garay-Arroyo and Covarrubias 1999). Its sequence analysis shows close relation with the reductases from the xylose fermenting yeasts (Kuhn et al. 1995).

The strain carrying GRE3 was observed to have the highest specific XR activity followed by the strain carrying $C t X R$ over the control strain (Fig. 2d). The specific xylose consumption rate and xylitol productivity both were found to be significantly higher in the strain carrying GRE3 gene followed by the strain carrying CtXR gene around 34 and $28 \mathrm{mgg}^{-1} \mathrm{~h}^{-1}$, respectively. The highest specific XR activity (Fig. 3a) and xylitol productivity (Fig. 3b) were observed in the early phase of fermentation which decreased at later time points. Expression of the genes $P S X R$ and $N c X R$ did not lead to a significant improvement in the xylitol productivity over the control, as shown in Fig. 2. This could be attributed to the higher $K_{\mathrm{m}}$ values for xylose of these enzymes $(34,42 \mathrm{mM}$, respectively) as compared with the product of the gene GRE3 (13.6 mM) (Woodyer et al. 2005). NcXR has been reported to enhance the fermentation of xylose when cloned in xylitol dehydrogenase (XDH) deleted strain of C. tropicalis (Jeon et al. 2012). However, the overall consumption of xylose and xylitol productivity of the $S$. cerevisiae strain carrying $N c X R$ was not significantly higher than the control strain (Fig. 2). The relative differences in the specific xylitol productivity (Fig. 2b) of different strains over time showed that the overall fermentation efficiency was dependent on the efficiency of the enzyme as well as the mitotic stability of the cells over the same amount of biomass in the broth. These observations highlighted that the production of xylitol was only regulated by the efficiency of the reductase enzyme during fed batch fermentation. This limitation was overcome by overexpression of the appropriate gene in these strains along with the xylose transporter.
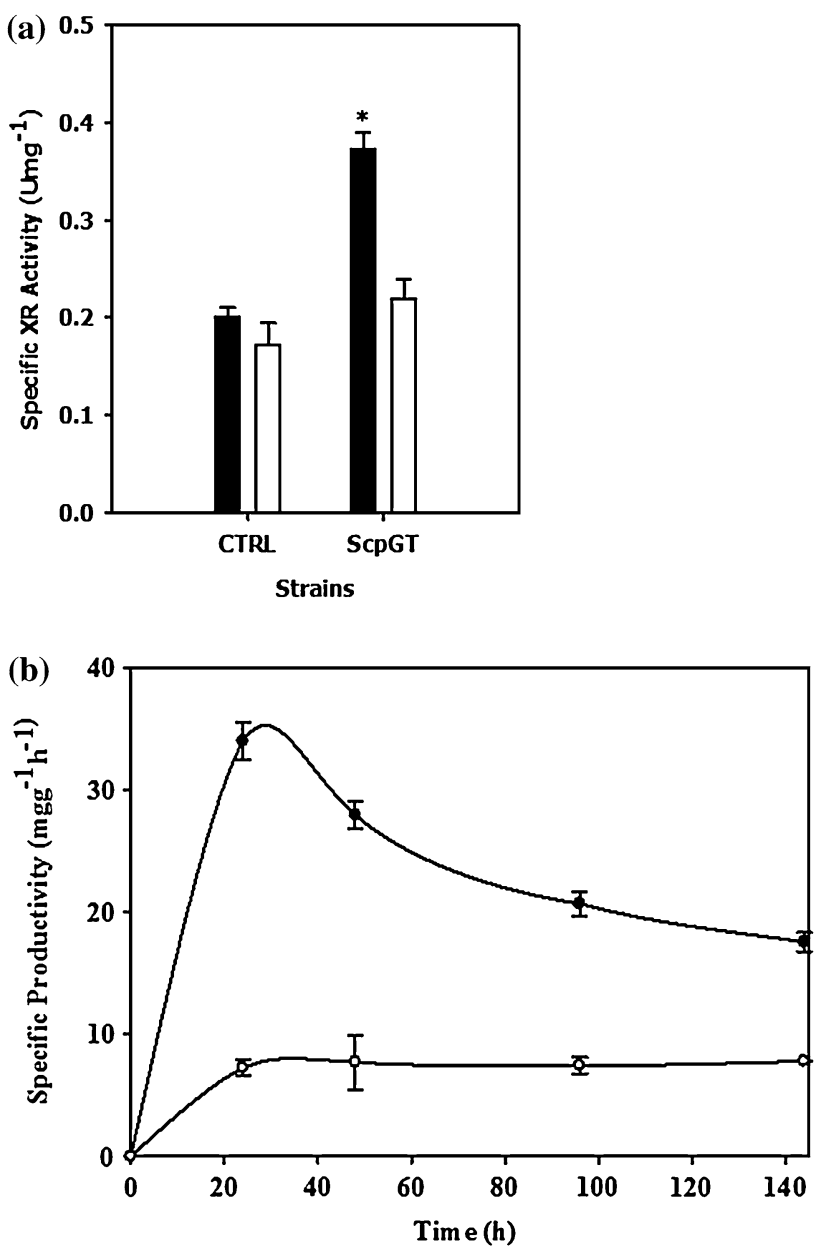

Fig. 3 Mitotic instability of recombinant strain leads to decrease in xylitol productivity a specific XR activity of Sc pGT (dark fill) and control (no fill) and $\mathbf{b}$ specific productivity of $S$. cerevisiae overexpressing GRE3 gene ScpGT (solid symbols) and control (empty symbols) over time. Values are expressed as Mean \pm S.E. $(n=2)$

Ethanol was produced from the glucose consumed during fed batch fermentation, and xylose was converted to only xylitol, as the gene coding for the enzyme xylitol dehydrogenase is not present in $S$. cerevisiae to further metabolise xylitol. The efficiency of ethanol production was determined as the ratio of the yield of ethanol obtained to the theoretical maximum ethanol yield $(0.51 \mathrm{~g}$ per $\mathrm{g}$ glucose). All the recombinant $S$. cerevisiae strains showed ethanol production efficiency in the range of 38-45 \% from the glucose during fed batch fermentation (Table 6). The profiles of the xylose consumed, xylitol produced along with the amount of ethanol formed over time by the control, and GRE3 overexpressing strains have been shown in Fig. 4. The figure shows that the rate of xylose consumption by the strain overexpressing GRE3 gene was higher than the control strain, while the accumulation of ethanol followed almost similar trend in both strains indicating a 
Table 6 Ethanol production by the recombinant $S$. cerevisiae strains

\begin{tabular}{llll}
\hline Strain & $\begin{array}{l}\text { Ethanol } \\
\text { titer }\left(\mathrm{gL}^{-1}\right)\end{array}$ & $Y_{\mathrm{p} / \mathrm{s}}\left(\mathrm{gg}^{-1}\right)^{\mathrm{a}}$ & Efficiency $(\%)^{\mathrm{b}}$ \\
\hline Sc RT & 23.36 & 0.22 & 44.04 \\
Sc CT & 22.81 & 0.22 & 43.00 \\
Sc PT & 21.83 & 0.21 & 41.17 \\
Sc NT & 23.87 & 0.23 & 45.01 \\
Sc control & 20.32 & 0.20 & 38.31
\end{tabular}

a Yield of ethanol produced on glucose consumed

b Percent efficiency of the yield obtained and the theoretical maximum of ethanol on glucose

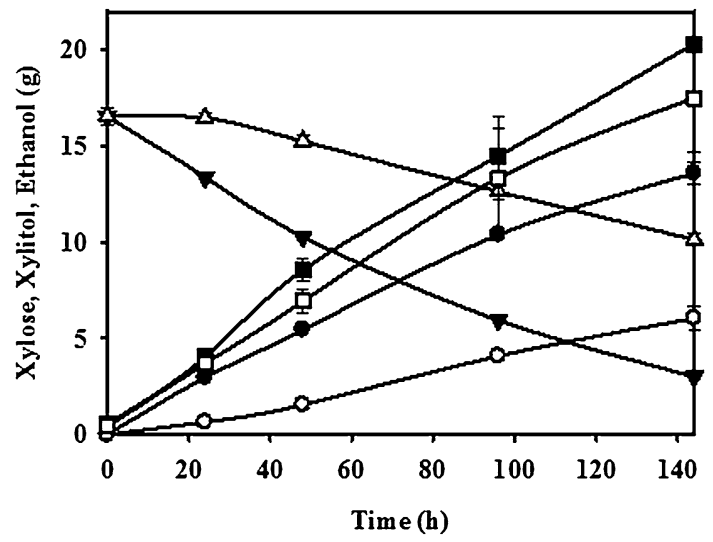

Fig. 4 Fermentation profiles of control (empty symbols) and ScpGT (filled symbols) strains, where Xylitol—circle, Xylose-triangle, and Ethanol-square. Values are expressed as Mean \pm S.E. $(n=2)$. Asterisk indicates a significant difference $(p<0.005)$ when compared to the control group

constant rate of glucose metabolism without accumulating it in the broth.

We compared the xylose fermentation efficiency of the recombinant $S$. cerevisiae strains in media containing synthetic xylose as well as in non-detoxified hemicellulosic hydrolysate of corn cob. It was observed that there was no significant difference in the fermentation efficiencies in two media, as shown in Table 7. The comparison of the fermentation efficiencies in both the media confirmed that S. cerevisiae is the most suitable host for the processes involving industrially relevant media. The organisms belonging to the genus Candida have been extensively reported for high xylitol productivities (Ko et al. 2006). However, the reported yield of xylitol in fermentation of hemicellulosic hydrolysate is lower than that in the pure substrate (Walther et al. 2001; Choi et al. 2000). This is mainly due to the presence of inhibitory compounds arising from the pretreatment of biomass and the loss of xylose for cell growth or ethanol produced. As given in Table 4, the media used in this study contained the inhibitory
Table 7 Fed batch fermentation with $S$. cerevisiae overexpressing GRE3 with SUT1 in synthetic xylose and hemicelullosic hydrolysate of corn cob (HHCC) was comparable

\begin{tabular}{|c|c|c|c|}
\hline \multicolumn{2}{|c|}{ Xylose consumed (\%) } & \multicolumn{2}{|c|}{ Titer $\left(\mathrm{gL}^{-1}\right)$} \\
\hline HHCC & Synthetic & HHCC & Synthetic \\
\hline 84.4 & 80.9 & 22.4 & 19.7 \\
\hline
\end{tabular}

compounds furfural, HMF, phenolics, and acetic acid at concentrations which are otherwise inhibitory to the metabolism and growth of the microorganisms, such as $C$. tropicalis. $S$. cerevisiae demonstrates a natural tolerance against such fermentation and metabolic inhibitors by the virtue of elevated function of the PPP and oxido-reductase enzymes giving it an advantage over other organisms (Celton et al. 2012).

\section{Specific XR activity estimation in fermentation samples}

The maximum specific XR activities were attained by all the recombinant strains at the start of the xylose fermentation phase when residual glucose was not observed in the broth. The specific XR activity in the strain overexpressing GRE3 gene was found to be $0.37 \mathrm{Umg}^{-1}$ which was a significant improvement of 1.9 fold over the control strain. The strains carrying $C t X R, P s X R$, and $N c X R$ genes showed $1.7,1.5$, and 1.3 fold specific XR activities, respectively, as compared to the control, as shown in Fig. 2d. Under the same host and vector system, GRE3 gene showed the highest activity in $S$. cerevisiae resulting into highest productivity of xylitol.

Other studies on overexpression of GRE3 along with different dehydrogenases and xylulose kinase (XKS1) genes in $S$. cerevisiae are focused on the improved fermentation of xylose to ethanol (Konishi et al. 2015; Khattab and Kodaki 2014). Similar to our findings, the authors have reported that the overexpression of GRE3 gene leads to higher xylose fermentation. However, these studies are limited to the comparison of the fermentation efficiency of $S$. cerevisiae strains carrying GRE3 and $X R$ from $P$. stipitis for ethanol production. In another report on xylitol production by the $S$. cerevisiae, the efficiency of the strains expressing GRE3 and XR from $P$. stipitis was compared (Kim et al. 2002). The authors have reported that in spite of the similar amounts of enzyme expression, the strain expressing GRE3 showed lower xylitol productivity due to its strong preference to NADPH, unlike $P$. stipitis $X R$ which also accepted NADH as cofactor. In our study, continuous glucose feeding strategy ensured a sufficient regeneration of NADPH for the activity of xylose 
reductase. We have found that under the same expression system, the enzyme activity of $C t X R$ was also higher than $P s X R$ leading to a higher xylose consumption rate.

\section{Effect of mitotic instability during fermentation}

Since the expression system was a plasmid-based episomal system, loss of plasmid by cells was observed in the absence of selection pressure. This eventually led to the decrease in XR activity with progress of fermentation. It was observed that only up to $50 \%$ of cells could stably retain plasmids at the end of fermentation. The effect of plasmid loss on the specific XR activity and xylitol productivity is shown in Fig. 3. The strain overexpressing GRE3 gene showed about $50 \%$ decrease in the reductase activity (Fig. 3a) and specific productivity of xylitol (Fig. 3b). However, the specific xylitol productivity of the control strain was constant throughout fermentation, since the enzyme activity of the genome encoded GRE3 gene was constant with respect to the biomass, as shown in Fig. 3a.

\section{Conclusion}

This is the first report on xylitol production using nondetoxified hemicellulosic hydrolysate of corn cob by recombinant S. cerevisiae. As a GRAS organism, S. cerevisiae is a preferable biocatalyst with high tolerance to inhibitory compounds present in hemicellulosic hydrolysates. It converts xylose to xylitol with near theoretical yield, whereas Candida sp. also utilizes it for cell growth. In the present study, a systematic evaluation of different reductase genes was done in recombinant $S$. cerevisiae containing heterologous xylose transporter. The strain overexpressing the endogenous GRE3 gene along with the xylose transporter gene SUT1 showed the highest xylitol productivity over control as compared to the strains carrying $C$. tropicalis, $P$. stipitis, and $N$. crassa xylose reductases. The fed batch process involved feeding of cosubstrate glucose, which could be available in the biorefineries based on cellulosic substrates. Ethanol produced from the glucose fed during process can be recovered from the fermentation broth to improve the overall process economics. It can also help in the prevention of contamination during fermentation in the hydrolysate-based media. Fermentation was conducted under microaerobic conditions which was lesser than the aeration required for xylitol production by other naturally xylose fermenting yeast species, such as Candida.

Acknowledgments This work was supported by the Praj Industries Ltd. We would like to thank Analytical Sciences department at Praj
Matrix for the analysis of samples and Mr. Siddharth Pal for providing hemicellulosic hydrolysate of corn cob.

\section{Compliance with ethical standards}

Conflict of interest Both the authors declare that there is no conflict of interest.

Ethical approval This article does not contain any studies with human participants or animals performed by any of the authors.

Open Access This article is distributed under the terms of the Creative Commons Attribution 4.0 International License (http:// creativecommons.org/licenses/by/4.0/), which permits unrestricted use, distribution, and reproduction in any medium, provided you give appropriate credit to the original author(s) and the source, provide a link to the Creative Commons license, and indicate if changes were made.

\section{References}

Almeida JRM, Modig T, Petersson A, Hahn-Hagerdal B, Liden G, Gorwa-Grauslund MF (2007) Increased tolerance and conversion of inhibitors in lignocellulosic hydrolysates by Saccharomyces cerevisiae. J Chem Technol Biotechnol 82:340-349. doi:10. $1002 /$ jctb. 1676

Amberg DC, Burke DJ, Strathern JN (2005) Methods in yeast genetics: a cold spring harbor laboratory course manual, 2005 edition (Cold Spring). Harbor Laboratory Press, NY

Barbosa MFS, Medeiros MB, Mancilha IM, Schneider H, Lee H (1988) Screening of yeasts for production of xylitol from D-xylose and some factors which affect xylitol yield in Candida guilliermondii. J Ind Microb 3:241-251

Bengtsson O, Hahn-Hägerdal B, Gorwa-Grauslund MF (2009) Xylose reductase from Pichia stipitis with altered coenzyme preference improves ethanolic xylose fermentation by recombinant Saccharomyces cerevisiae. Biotechnol Biofuels 2:9. doi:10.1186/ 1754-6834-2-9

Brachmann CB, Davies A, Cost GJ, Caputo E, Li J, Hieter P, Boeke JD (1998) Designer deletion strains derived from Saccharomyces cerevisiaeS288C: a useful set of strains and plasmids for PCRmediated gene disruption and other applications. Yeast 14:115-132

Celton M, Goelzer A, Camarasa C, Fromion V, Dequin S (2012) A constraint-based model analysis of the metabolic consequences of increased NADPH oxidation in Saccharomyces cerevisiae. Metab Eng 4:366-379. doi:10.1016/j.ymben.2012.03.008

Choi JH, Moon KH, Ryu YW, Seo JH (2000) Production of xylitol in cell recycle fermentations of Candida tropicalis. Biotech Lett 22:1625-1628

Chu BCH, Lee H (2007) Genetic improvement of Saccharomyces cerevisiae for xylose fermentation. Biotechnol Adv 25:425-441. doi:10.1016/j.biotechadv.2007.04.001

Chung YS, Kim MD, Lee WJ, Ryu YW, Kim JH, Seo JH (2002) Stable expression of xylose reductase gene enhances xylitol production in recombinant Saccharomyces cerevisiae. Enzyme Microb Tech 30:809-816

Cocotle-Ronzon Y, Zendejas-Zaldo M, Castillo-Lozano ML, AguilarUscanga M (2012) Preliminary characterization of xylose reductase partially purified by reversed micelles from Candida tropicalis IEC5-ITV, an indigenous xylitol-producing strain. Adv Chem Eng Sci 2:9-14. doi:10.4236/aces.2012.21002

Dominguez JM, Gong CS, Tsao GT (1996) Pretreatment of sugar cane bagasse hemicellulose hydrolysate for xylitol production by yeast. Appl Biochem Biotechnol 57-58:49-56 
Garay-Arroyo A, Covarrubias AA (1999) Three genes whose expression is induced by stress in Saccharomyces cerevisiae. Yeast 15:879-892

Ghindea R, Csutak O, Stoica I, Tanase AM, Vassu T (2010) Production of xylitol by yeasts. Rom Biotechnol Lett 15:5217-5222

Hamacher T, Becker J, Gardonyi M, Hahn-Hagerdal B, Boles B (2002) Characterization of the xylose-transporting properties of yeast hexose transporters and their influence on xylose utilization. Microbiology 148:2783-2788

Hector RE, Mertens JA, Bowman MJ, Nichols NN, Cotta MA, Hughes SR (2011) Saccharomyces cerevisiae engineered for xylose metabolism requires gluconeogenesis and the oxidative branch of the pentose phosphate pathway for aerobic xylose assimilation. Yeast 28:645-660. doi:10.1002/yea.1893

Heer D, Heine D, Sauer U (2009) Resistance of Saccharomyces cerevisiae to high concentrations of furfural is based on NADPH-dependent reduction by at least two oxireductases. Appl Environ Microbiol 75:7631-7638. doi:10.1128/AEM. 01649-09

Hu C, Zhao X, Zhao J, Wu S, Zhao ZK (2009) Effects of biomass hydrolysis by-products on oleaginous yeast Rhodosporidium toruloides. Biores Technol 100:4843-4847. doi:10.1016/j. biortech.2009.04.041

Jeon WY, Yoon BH, Ko BS, Shim WY, Kim JH (2012) Xylitol production is increased by expression of codon-optimized Neurospora crassa xylose reductase gene in Candida tropicalis. Bioprocess Biosyst Eng 35:191-198. doi:10.1007/s00449-0110618-8

Karhumaa K, Hahn-Hägerdal B, Gorwa-Grauslund MF (2005) Investigation of limiting metabolic steps in the utilization of xylose by recombinant Saccharomyces cerevisiae using metabolic engineering. Yeast 22:359-368. doi:10.1002/yea.1216

Katahiraa S, Itoa M, Takemab H, FujitaY TT, Tanakac T, Fukudac H, Kondo A (2008) Improvement of ethanol productivity during xylose and glucose co-fermentation by xylose-assimilating $S$. cerevisiae via expression of glucose transporter Sut1. Enzyme Microb Technol 43:115-119

Khattab S, Kodaki T (2014) Efficient bioethanol production by overexpression of endogenous Saccharomyces cerevisiae xylulokinase and NADPH-dependent aldose reductase with mutated strictly $\mathrm{NADP}^{+}$-dependent Pichia stipitis xylitol dehydrogenase. Process Biochem 49:1838-1842

Kim MD, Jeun YS, Kim SG, Ryu YW, Seo JH (2002) Comparison of xylitol production in recombinant Saccharomyces cerevisiae strains harboring XYL1 gene of Pichia stipitis and GRE3 gene of S. cerevisiae. Enzyme Microb Technol 31:862-866. doi:10. 1016/S0141-0229(02)00192-8

Ko BS, Kim J, Kim JH (2006) Production of xylitol from D-xylose by a xylitol dehydrogenase gene-disrupted mutant of Candida tropicalis. Appl Environ Microbiol 72:4207-4213. doi:10.1128/ AEM.02699-05

Konishi J, Fukuda A, Mutaguchi K, Uemura T (2015) Xylose fermentation by Saccharomyces cerevisiae using endogenous xylose-assimilating genes. Biotech Lett 37:1623-1630. doi:10. 1007/s10529-015-1840-2

Kuhn A, van Zyl C, Tonder AV, Prior BA (1995) Purification and partial characterization of an aldo-ketoreductase from Saccharomyces cerevisiae. Appl Environ Microbiol 61:1580-1585

Leathers TD (2003) Bioconversions of maize residues to value-added coproducts using yeast-like fungi. FEMS Yeast Res 3:133-140. doi:10.1016/S1567-1356(03)00003-5

Lowry OH, Rosenbrough NJ, Farr AL, Randall RJ (1951) Protein measurement with the Folin phenol reagent. J Biol Chem 193(1):265-275

Menon V, Prakash G, Rao M (2010) Value added products from hemicellulose: biotechnological perspective. Glob J Biochem $1: 36-67$

Mohamad NL, Mustapa Kamal SM, Mokhtara MN (2015) Xylitol biological production: a review of recent studies. Food Rev Int 31:74-89. doi:10.1080/87559129.2014.961077

Nevoigt E (2008) Progress in metabolic engineering of Saccharomyces cerevisiae. Microbiol Mol Biol Rev 72:379-412. doi:10.1128/MMBR.00025-07

Parajo JC, Dominguez H, Dominguez JM (1998a) Biotechnological production of xylitol. Part 1: interest of xylitol and fundamentals of its biosynthesis. Biores Technol 65:191-201

Parajo JC, Dominguez H, Dominguez JM (1998b) Biotechnological production of xylitol. Part 3: operation in culture media made from lignocellulose hydrolysates. Biores Technol 66:25-40

Ping Y, Ling HZ, Song G, Ge JP (2013) Xylitol production from nondetoxified corncob hemicellulose acid hydrolysate by Candida tropicalis. Biochem Eng J 75:86-91. doi:10.1016/j.bej.2013.03. 022

Saha BC (2003) Hemicellulose bioconversion. J Ind Microbiol Biotechnol 30:279-291. doi:10.1007/s10295-003-0049-x

Schwartz K, Wenger JW, Dunn B, Sherlock G (2012) APJ1 and GRE3 homologs work in concert to allow growth in xylose in a natural Saccharomyces sensu stricto hybrid yeast. Genetics 191:621-632. doi:10.1534/genetics.112.140053

Verduyn C, Van Kleef R, Frank J, Schreuder H, Van Dijken JP, Scheffers WA (1985) Properties of the NAD(P)H-dependent xylose reductase from the xylose fermenting yeast Pichia stipitis. Biochem J 226:669-677

Walther T, Hensirisak P, Agblevor FA (2001) The influence of aeration and hemicellulosic sugars on xylitol production by Candida tropicalis. Biores Technol 76:213-220

Woodyer R, Simurdiak M, Donk W, Zhao H (2005) Heterologous expression, purification, and characterization of a highly active xylose reductase from Neurospora crassa. Appl Environ Microbiol 71:1642-1647. doi:10.1128/AEM.71.3.1642-1647. 2005

Zhang J, Zhang B, Wang D, Gao X, Hong J (2013) Xylitol production at high temperature by engineered Kluyveromyces marxianus. Biores Technol 152:192-201. doi:10.1016/j.biortech.2013.10. 109 